\title{
Self-assembly and semiconductivity of an oligothiophene supergelator
}

\author{
Pampa Pratihar ${ }^{1}$, Suhrit Ghosh ${ }^{1,2}$, Vladimir Stepanenko ${ }^{1}$, \\ Sameer Patwardhan ${ }^{3}$, Ferdinand C. Grozema ${ }^{3}$, Laurens D. A. Siebbeles ${ }^{3}$ \\ and Frank Würthner ${ }^{* 1}$
}

\section{Full Research Paper}

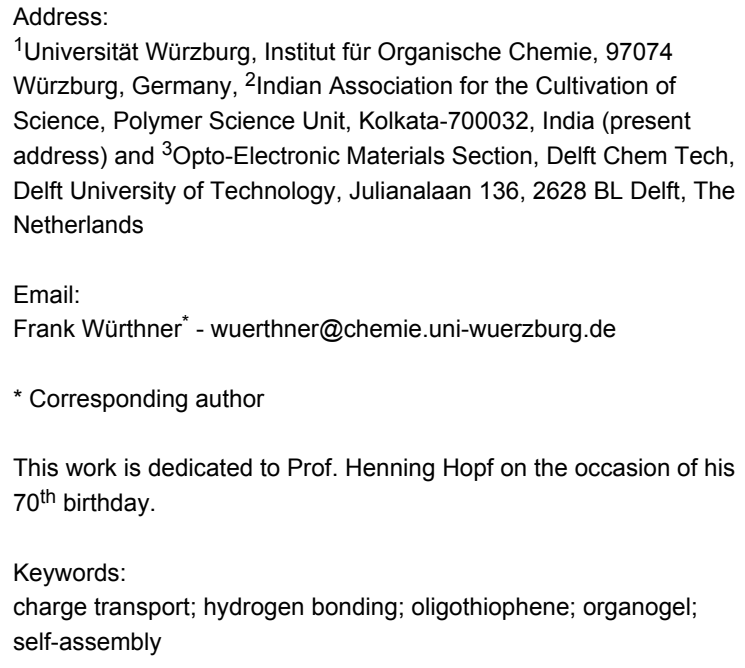

${ }^{1}$ Universität Würzburg, Institut für Organische Chemie, 97074 Würzburg, Germany, ${ }^{2}$ Indian Association for the Cultivation of Science, Polymer Science Unit, Kolkata-700032, India (present address) and ${ }^{3}$ Opto-Electronic Materials Section, Delft Chem Tech, Delft University of Technology, Julianalaan 136, 2628 BL Delft, The Netherlands

Email:

Frank Würthner* - wuerthner@chemie.uni-wuerzburg.de

* Corresponding author

This work is dedicated to Prof. Henning Hopf on the occasion of his $70^{\text {th }}$ birthday.

Keywords:

charge transport; hydrogen bonding; oligothiophene; organogel; self-assembly

\author{
Beilstein J. Org. Chem. 2010, 6, 1070-1078 \\ doi:10.3762/bjoc.6.122 \\ Received: 15 June 2010 \\ Accepted: 05 August 2010 \\ Published: 16 November 2010 \\ Guest Editor: J.-P. Desvergne \\ (c) 2010 Pratihar et al; licensee Beilstein-Institut. \\ License and terms: see end of document.
}

\begin{abstract}
A bis(trialkoxybenzamide)-functionalized quaterthiophene derivative was synthesized and its self-assembly properties in solution were studied. In non-polar solvents such as cyclohexane, this quaterthiophene $\pi$-system formed fibril aggregates with an $\mathrm{H}$-type molecular arrangement due to synergistic effect of hydrogen bonding and $\pi$-stacking. The self-assembled fibres were found to gelate numerous organic solvents of diverse polarity. The charge transport ability of such elongated fibres of quaterthiophene $\pi$-system was explored by the pulse radiolysis time resolved microwave conductivity (PR-TRMC) technique and moderate mobility values were obtained. Furthermore, initial AFM and UV-vis spectroscopic studies of a mixture of our electron-rich quaterthiophene derivative with the electron acceptor [6,6]-phenyl- $\mathrm{C}_{61}$-butyric acid methyl ester (PCBM) revealed a nanoscale segregated assembly of the individual building blocks in the blend.
\end{abstract}

\section{Introduction}

Self-assembly provides a spontaneous pathway to generate higher-order structures from suitably designed building blocks by virtue of specific intra and intermolecular non-covalent interactions [1]. The development of such building blocks contain- ing various functional $\pi$-systems has attracted much interest in the recent past due to their potential applications as active components in a variety of organic electronic devices [2]. Organogels are a special class of self-assembled materials in 
which small building blocks generate fibrous structures due to intermolecular non-covalent interactions, and these elongated fibres form interpenetrating network in which the solvent molecules are trapped $[3,4]$. Organogels based on various $\pi$-systems such as oligophenylenevinylenes [5] and thienylenevinylenes [6] oligophenyleneethylenes [7], phthalocyanines [8], porphyrins [9], naphthalene and perylene bisimides [10-12], acenes $[13,14]$ and merocyanines $[15,16]$ have been studied in recent years. Self-assembly of various oligothiophene derivatives have been extensively investigated on account of their semiconducting and optoelectronic properties [17]. Feringa and co-workers reported organogels based on bisurea derivatives of bithiophene chromophores and demonstrated a significant charge carrier mobility as a result of self-assembly $\left(\Sigma \mu_{\min }=5 \times\right.$ $10^{-3} \mathrm{~cm}^{2} \mathrm{~V}^{-1} \mathrm{~s}^{-1}$ ) [18]. However, the building blocks were made only from mono and bithiophene units. Later, Shinkai and co-workers reported the gelation ability of quaterthiophene and hexathiophene derivatives with peripheral amide-linked cholesterol moieties [19]. We recently reported [12] the self-assembly of perylene bisimide (PBI) $\pi$-systems that are functionalized with trialkoxybenzamide moiety and have shown that they possess much superior and versatile gelation and self-assembly properties compared to those of cholesterol-linked PBI gelators reported earlier [10]. We also have demonstrated that the trialkoxybenzamide units provide a unique opportunity to tune the mode of self-assembly (H-type vs. J-type) of PBIs by systematically varying the steric crowding in the peripheral alkyl groups [20,21]. These recent findings on PBI gelators prompted us to explore the utility of similar supramolecular design on the self-assembly of other functional $\pi$-systems.

Herein we describe the synthesis, self-assembly, gelation, and charge-carrier mobility studies of trialkoxybenzamide-functionalized quaterthiophene derivative T1 (Scheme 1). We also present our initial results on the morphology of blends of this electron-rich p-type semiconducting $\mathbf{T 1}$ with the well-known n-type semiconductor $[6,6]$-phenyl- $\mathrm{C}_{61}$-butyric acid methyl ester (PCBM).

\section{Results and Discussions Synthesis}

The synthetic route to the newly designed quaterthiophene derivative $\mathbf{T 1}$ is depicted in Scheme 2. Compounds 4 [22] and 5
[20] were synthesized from commercially available starting materials in a few synthetic steps by literature methods, and then coupled together to produce the thiophene-containing building block 6 in $78 \%$ yield. 2, 2'-Bithiophene was converted to the corresponding tributyltin derivative 8 by the reported procedure [19] and then coupled with compound 6 in the presence of a Pd-catalyst to give the desired oligothiophene derivative T1 in $82 \%$ yield. The new compounds 6 and T1 were characterized by ${ }^{1} \mathrm{H}$ NMR and UV-vis spectroscopy, HRMS (ESI) and elemental analysis, while those synthetic intermediates already reported in the literature were characterized by ${ }^{1} \mathrm{H}$ NMR and UV-vis spectroscopy.

\section{Gelation tests}

The gelation properties of $\mathbf{T 1}$ were examined in various organic solvents (Table 1) at a concentration of $3.5 \mathrm{mM}$. At room temperature T1 was soluble only in chloroform, dichloromethane, and tetrahydrofuran among other tested solvents. However, at elevated temperatures this quaterthiophene could be dissolved in all the tested solvents and when the hot solution was cooled down to room temperature, spontaneous gelation was observed (see Figure 1A, inset) in most cases within 5-10 minutes. For example, aromatic hydrocarbons (toluene, benzene), aliphatic hydrocarbons (methylcyclohexane, cyclohexane, $n$-heptane, $n$-hexane), chlorinated hydrocarbons (chlorobenzene, tetrachloroethylene, 1,2-dichloroethane), ethers (dibutyl ether, THF, dioxan), hydrogen-bonding donor molecules (triethylamine, acetone), and even highly polar solvents such as DMF and ethanol could be gelated with T1. The only exceptions were acetonitrile and DMSO for which no gelation was observed. Critical gelation concentrations (CGC) were determined for all the solvents gelated with $\mathbf{T} 1$ and found to be below $0.3 \mathrm{wt} \%$. This CGC value is much lower compared to those of the previously reported quaterthiophene gelators containing cholesteryl amide peripheral groups [19]. It is interesting to note that in aliphatic hydrocarbons (methylcyclohexane $(\mathrm{MCH})$, cyclohexane, $n$-hexane, $n$-heptane) and in tetrachloroethylene the CGC values are even less than $0.1 \mathrm{wt} \%$. Organogelators with such low CGC values are classified as supergelators [4], and thus the present quaterthiophene gelator T1 belongs to this category. The ability of T1 to gelate such a wide range of solvents and its significantly low CGC values can be attributed to the favourable balance between the self-

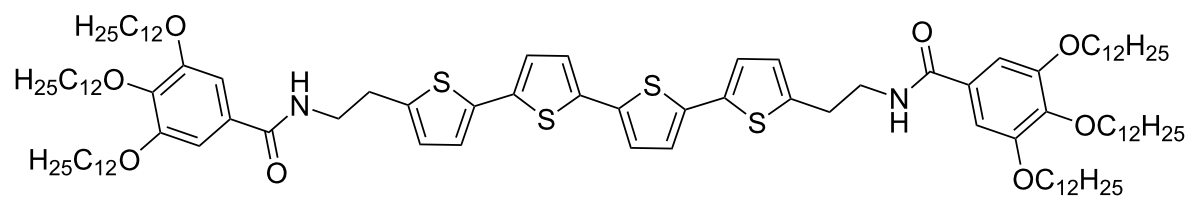




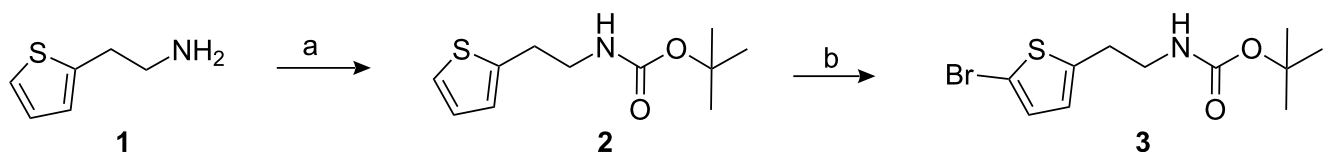

1

2

3

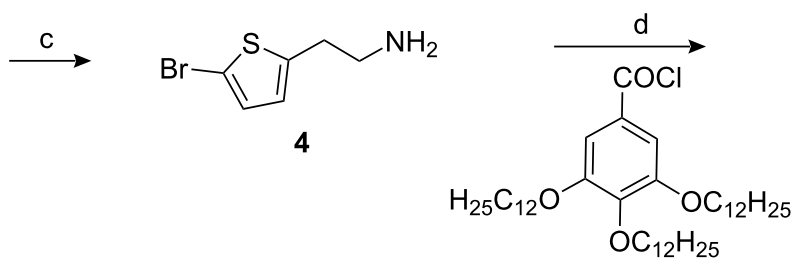<smiles>CCOc1cc(C(=O)NCCc2ccc(Br)s2)cc(OCC)c1OCC</smiles>

5

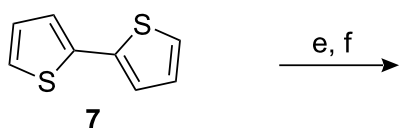<smiles>CCCCCc1ccc(-c2ccc(C(CCCC)CC(C)(C)C)s2)s1</smiles>

$6+8$

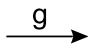<smiles>CCCCCCCCCNC(=O)c1cc(OCCC)c(OCCC)c(OCCC)c1</smiles>

Scheme 2: Synthetic route to T1. Reagent and conditions: a) Boc anhydride, $\mathrm{CH}_{2} \mathrm{Cl}_{2}, 6 \mathrm{~h}, 0{ }^{\circ} \mathrm{C}-\mathrm{rt}, 97 \%$; b) NBS, DMF, rt, $\left.12 \mathrm{~h}, 89 \% ; \mathrm{c}\right) \mathrm{TFA} \mathrm{CH}_{2} \mathrm{Cl}_{2}$, rt, 4 h, 99\%; d) $\mathrm{Et}_{3} \mathrm{~N}, \mathrm{CH}_{2} \mathrm{Cl}_{2}, 0{ }^{\circ} \mathrm{C}-\mathrm{rt}, 78 \%$; e) BuLi, THF, $0{ }^{\circ} \mathrm{C}, 1 \mathrm{~h}$; f) $\left.\mathrm{Bu}_{3} \mathrm{SnCl}, \mathrm{rt}, 12 \mathrm{~h} ; \mathrm{g}\right) \mathrm{Pd}\left(\mathrm{PPh}_{3}\right)_{2} \mathrm{Cl}_{2}, \mathrm{DMF}, 80^{\circ} \mathrm{C}, 8 \mathrm{~h}, 82 \%$.

\begin{tabular}{|c|c|c|c|c|}
\hline Entry & Solvent & Observation & CGC (moles/lit.) & CGC (Wt \%) \\
\hline 1 & Toluene & G & $1 \times 10^{-3}$ & 0.20 \\
\hline 2 & Benzene & G & $1 \times 10^{-3}$ & 0.19 \\
\hline 3 & Methylcyclohexane & G & $2 \times 10^{-4}$ & 0.04 \\
\hline 4 & Cyclohexane & G & $4 \times 10^{-4}$ & 0.08 \\
\hline 5 & $n$-Heptane & G & $3.75 \times 10^{-4}$ & 0.09 \\
\hline 6 & $n$-Hexane & G & $0.4 \times 10^{-3}$ & 0.10 \\
\hline 7 & $\mathrm{CHCl}_{3}$ & soluble & - & - \\
\hline 8 & $\mathrm{CH}_{2} \mathrm{Cl}_{2}$ & soluble & _- & _ \\
\hline 9 & Chlorobenzene & $G$ & $0.33 \times 10^{-2}$ & 0.51 \\
\hline 10 & Tetrachloroethylene & G & $9.09 \times 10^{-4}$ & 0.09 \\
\hline 11 & 1,2-Dichloroethylene & G & $1.25 \times 10^{-3}$ & 0.17 \\
\hline 12 & 1,4-Dioxan & $\mathrm{G}^{\mathrm{a}}$ & $0.125 \times 10^{-2}$ & 0.26 \\
\hline 13 & THF & soluble & - & _ \\
\hline 14 & Dibutylether & G & $1 \times 10^{-3}$ & 0.22 \\
\hline 15 & Acetone & $\mathrm{G}^{\mathrm{a}}$ & $1.11 \times 10^{-3}$ & 0.24 \\
\hline 16 & Triethylamine & G & $0.5 \times 10^{-3}$ & 0.12 \\
\hline 17 & Acetonitrile & not soluble & - & - \\
\hline 18 & DMF & G & $1 \times 10^{-3}$ & 0.18 \\
\hline 19 & DMSO & gel-like ppt. & - & _ \\
\hline 20 & Ethanol & $\mathrm{G}^{\mathrm{a}}$ & $1 \times 10^{-3}$ & 0.21 \\
\hline
\end{tabular}

aOpaque gel. 
assembly propensity of the gelator and good solubility due to the presence of the trialkoxybenzamide groups.

\section{AFM investigations}

The topology of gels of quaterthiophene derivative T1 was examined by atomic force microscopy (AFM) in the tapping mode. As an illustrative example, the AFM images of $\mathbf{T} 1$ gel in $\mathrm{MCH}$ deposited on highly ordered pyrolytic graphite (HOPG) are shown in Figure 1. These images clearly show interconnected long fibers a few micrometers in length and bundles that are responsible for the gelation of the solvents. At nanometer to micrometer resolution, a fibrous network is observed that contains smaller fibers (indicated by yellow arrows in Figure 1C) with a mean height of $2.3 \pm 0.3 \mathrm{~nm}$ and width of $7.0 \pm 1.0 \mathrm{~nm}$.

\section{Self-assembly studies by UV-vis spec- troscopy}

Self-assembly of $\mathbf{T 1}$ in solution was examined by UV-vis spectroscopy. Chloroform is known to be an excellent solvent for the study of rigid $\pi$-systems [20,21], and the oligothiophene chromophore T1 has good solubility in this solvent. However, as noted above, in nonpolar solvents such as $n$-heptane, gelation was observed at extremely low CGC values. Thus, we compared the UV-vis spectra of $\mathbf{T} \mathbf{1}$ in chloroform and $n$-heptane at $0.05 \mathrm{mM}$ concentration (Figure 2a).

In chloroform the $\pi-\pi^{*}$ transition band appeared at $400 \mathrm{~nm}$, whilst in $n$-heptane it was shifted significantly to a lower wavelength (374 nm). In $n$-heptane, additional shoulders appeared at 420,461 and $513 \mathrm{~nm}$ that were absent in the spectrum recorded

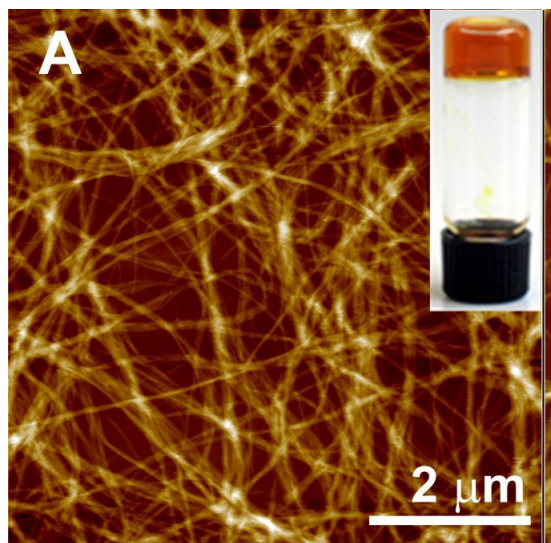

$0 \mathrm{~nm}$

$90 \mathrm{~nm}$

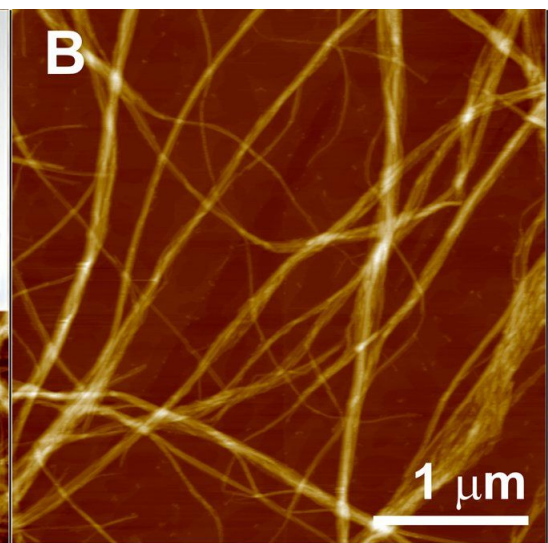

$0 \mathrm{~nm}$

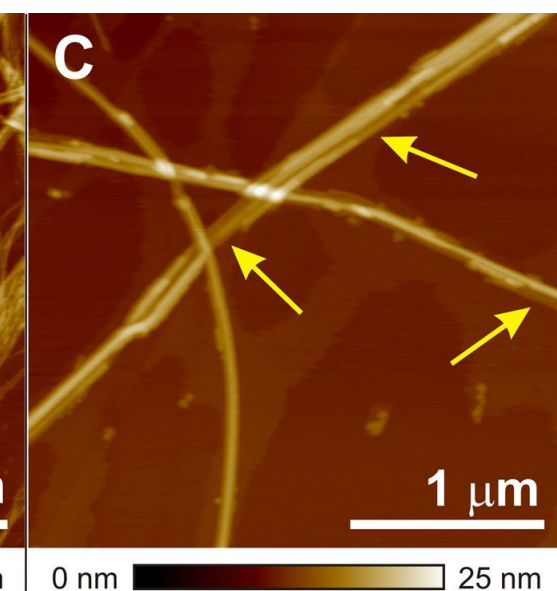

Figure 1: AFM height images of a film spin-coated from diluted gel solution of T1 in $\mathrm{MCH}\left(2 \times 10^{-3} \mathrm{M}\right)$ onto HOPG (A, B and C). The z scale (90, 60 and $25 \mathrm{~nm}$, respectively) is shown under the respective image. Inset in $1 \mathrm{~A}$ : a photograph of gel in cyclohexane at $1.5 \mathrm{mM}$ concentration.
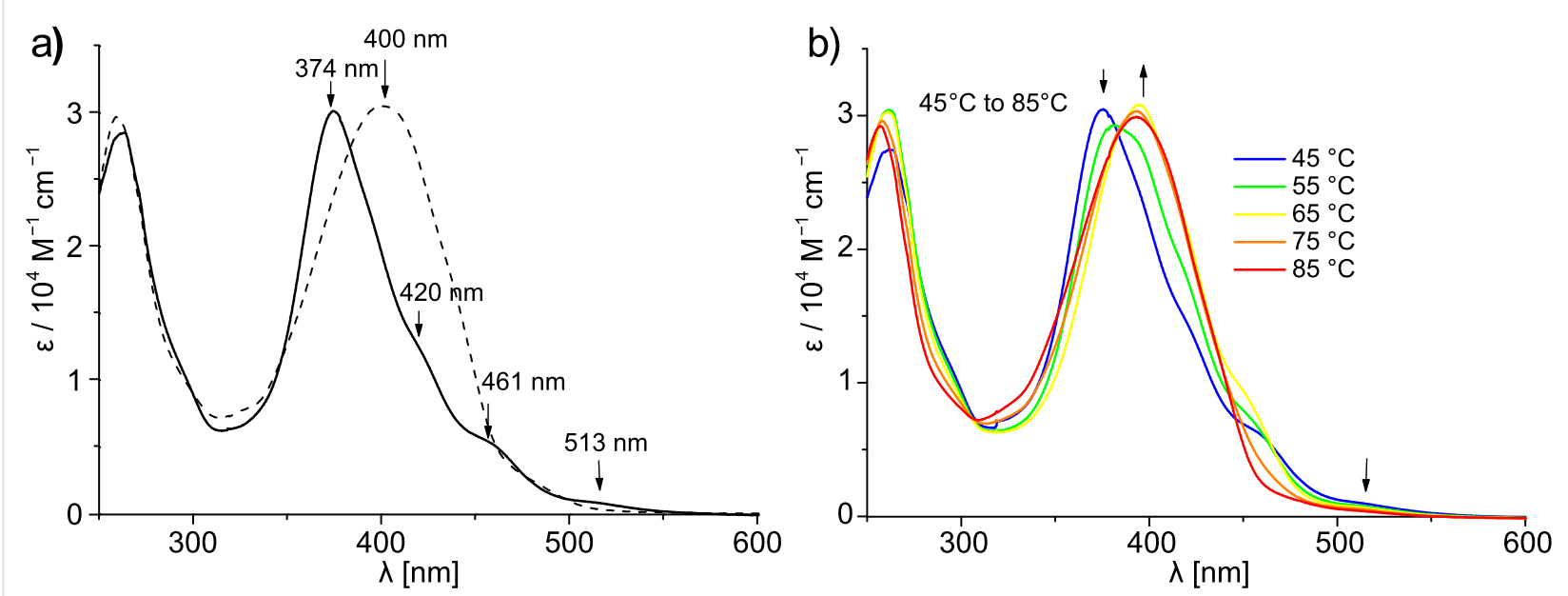

Figure 2: a) UV-vis spectra of T1 in chloroform (dashed line) and $n$-heptane (solid line); b) UV-vis spectra of T1 in $n$-heptane at different temperatures. Concentration of T1 is $5 \times 10^{-5} \mathrm{M}$. 
in chloroform. These results are in accord with the literature reports for the formation of $\mathrm{H}$-aggregates of oligothiophenes [19] and can be attributed to an excitonic interaction as well as an increase in the conformational order in the assembled state [23]. To test the reversibility of the self-assembly process, variable temperature UV-vis experiments were performed in $n$-heptane. These clearly showed that when the temperature was gradually raised from $45{ }^{\circ} \mathrm{C}$ to $85{ }^{\circ} \mathrm{C}$, the spectral pattern changed significantly (Figure $2 b$ ). The $\lambda_{\max }$ value shifted from $374 \mathrm{~nm}$ to $400 \mathrm{~nm}$ and the shoulders at higher wavelengths (420, 461 and $513 \mathrm{~nm}$ ) gradually disappeared. At the higher temperature, the spectrum resembles quite well that observed in chloroform solution (Figure 2a). These results suggest disassembly of the H-type aggregate to monomeric building blocks at elevated temperature. The self-assembly of $\mathbf{T} 1$ at such low concentrations can be attributed to the synergistic effect of $\pi-\pi$ stacking among the oligothiophene chromophores and intermolecular hydrogen bonding between the amide groups of the neighbouring chromophores (Scheme 3 ). To ascertain the involvement of hydrogen bonding in the self-assembly, we examined the effect of a protic solvent, e.g. $\mathrm{MeOH}$, on the selfassembly process by UV-vis spectroscopy. $\mathrm{MeOH}$ itself can be involved in H-bonding interaction with the amide groups, and thus expected to interfere with the inter-chromophoric hydrogen-bonding interaction and to disrupt the assembly. Note that, as methanol is not miscible with $n$-heptane, cyclohexane was used as nonpolar solvent for this experiment. It can be seen in Figure 3 that in the presence of $2.4 \% \mathrm{MeOH}$ the absorption spectrum of $\mathbf{T} 1$ in cyclohexane changed significantly. The shoulders at longer wavelength disappeared and the $\lambda_{\max }$ value shifted from $382 \mathrm{~nm}$ to $399 \mathrm{~nm}$, suggesting disassembly of the aggregate into monomers. Thus, it is evident that hydrogen bonding is essential for the self-assembly of T1, particularly at such a low concentration of $5 \times 10^{-5} \mathrm{M}$.

\section{Studies on blends of T1 with PCBM}

The fullerene derivative $[6,6]$-phenyl- $\mathrm{C}_{61}$-butyric acid methyl ester (PCBM) is a well-known n-type semiconductor and its blends with various electron-donor materials have been extensively used in solar cell devices [24]. The morphology of the blend of donor and acceptor materials plays a prominent role in device performance [25]. Recently, we reported that a n-type perylene bisimide organogelator exhibits photovoltaic activity with a p-type semiconducting polymer [26]. In this work, as an initial study we characterized the morphology of a mixture of PCBM with the p-type semiconducting oligothiophene-based gelator T1 to elucidate the prospect of this system being used as a photovoltaic material. Figure 4 depicts the AFM images of a mixture of T1 and PCBM on HOPG in which two types of aggregates are visible. The observed long fibers can be attributed to aggregates of $\mathbf{T 1}$ and the spherical nano-objects can be

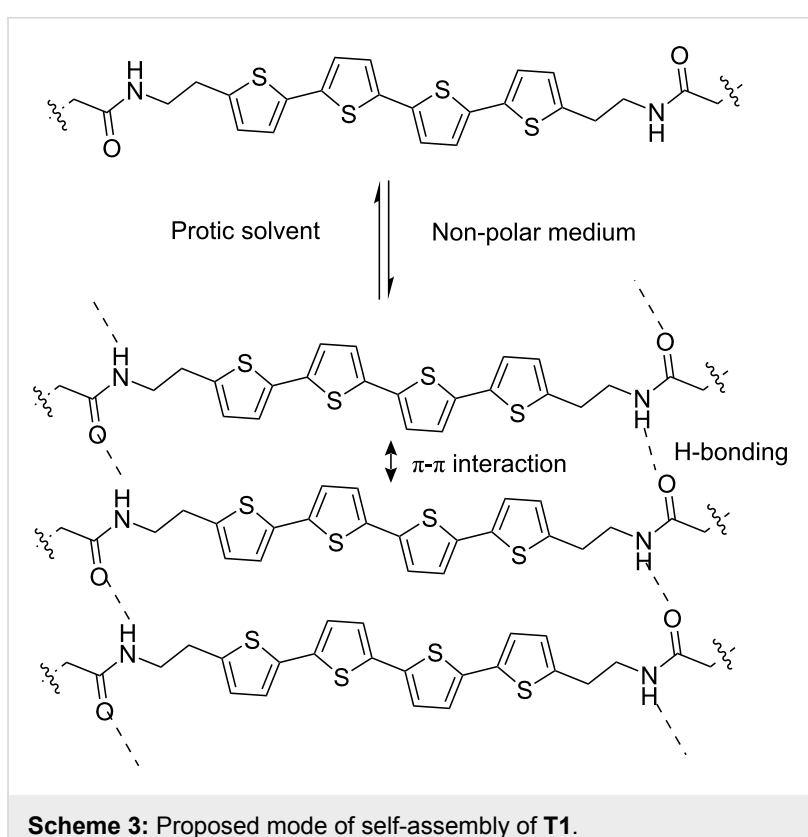

Scheme 3: Proposed mode of self-assembly of T1.

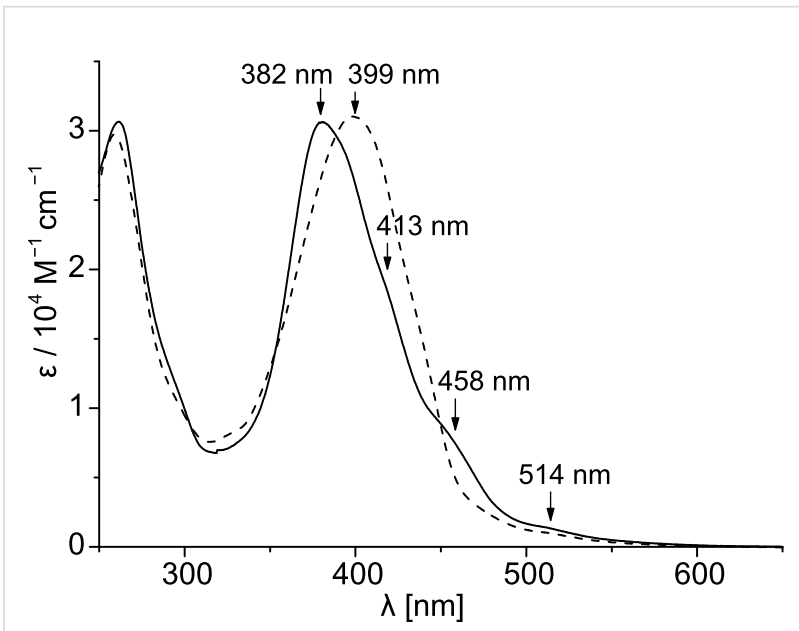

Figure 3: UV-vis spectra of T1 (concentration $5 \times 10^{-5} \mathrm{M}$ ) in cyclohexane (solid line) and $2.4 \% \mathrm{MeOH}$ in cyclohexane (dashed line) at $25^{\circ} \mathrm{C}$.

related to PCBM aggregates. The height and width of the long fibers were estimated to be $2.4 \pm 0.3 \mathrm{~nm}$ and $6.0 \pm 01.0 \mathrm{~nm}$, respectively, which very closely match with the values observed for the self-assembly of T1 alone (Figure 1). This indicates that PCBM does not interfere in the self-assembly of T1.

\section{Determination of charge carrier mobility}

It was anticipated that the well-organized $\pi$-stacked assembly of oligothiophene chromophores would provide percolation pathways for charge transport, similar to the previously reported results for mono- and bithiophene bisurea compunds [18]. Therefore, the charge transport properties of $\mathbf{T} 1$ in the solid 


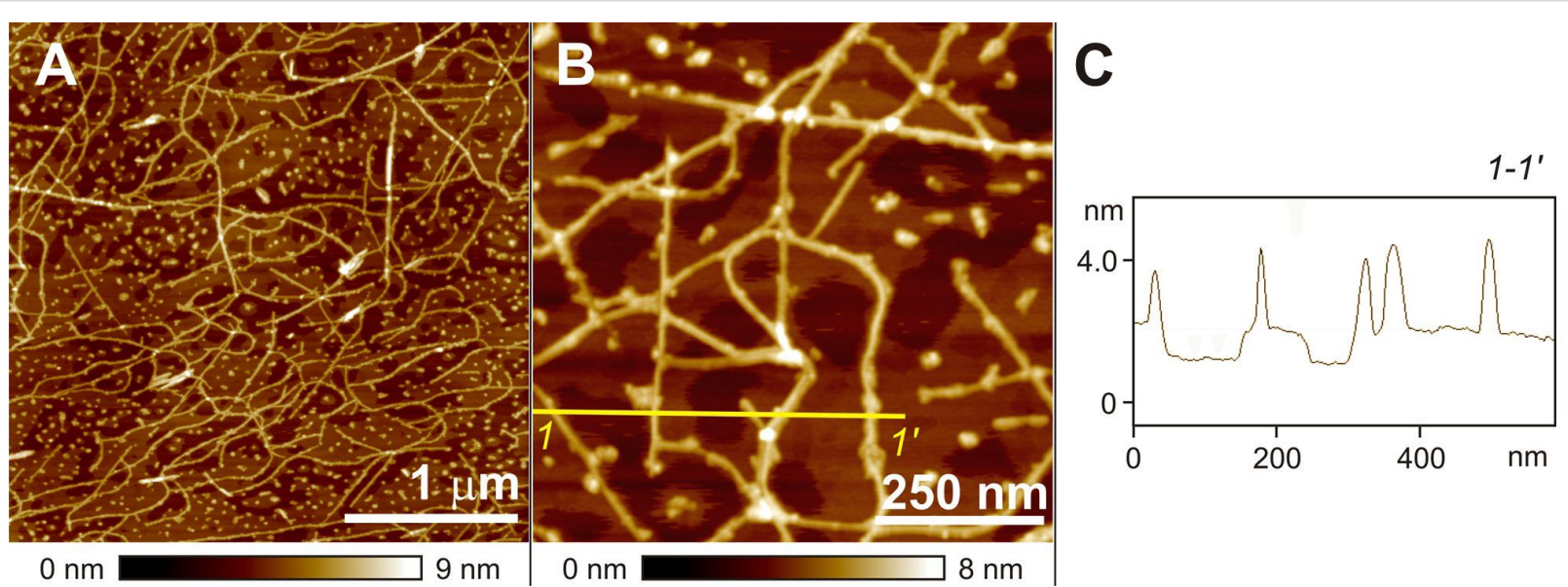

Figure 4: AFM height images ( $A$ and $B$ ) of a film spin-coated from $\mathrm{MCH}$ solution (concentration $5 \times 10^{-4} \mathrm{M}$ ) of a 1:1 mixture of T1 and PCBM onto HOPG. The $z$ scale $(9 \mathrm{~nm}$ and $8 \mathrm{~nm}$, respectively) is shown under the respective image. Figure $4 \mathrm{C}$ depicts cross-section analysis along the yellow line $1-1$ ' in image $B$.

state were investigated by pulse radiolysis time resolved microwave conductivity (PR-TRMC) measurements [27].

PR-TRMC measurements were performed with a solid (powder) sample of $\mathbf{T} \mathbf{1}$ using the same methodology as reported previously [27,28]. The sample $(\sim 32.5 \mathrm{mg})$ was irradiated with a short pulse of $3 \mathrm{MeV}$ electrons, which lead to the formation of charges in the material during the pulse. The conductivity was measured as a function of time by microwave conductivity measurements. The dose-normalized PR-TRMC transients for different irradiation doses at a temperature of $20^{\circ} \mathrm{C}$ are shown in Figure 5. The decay is the same for all irradiation doses, which indicates first order decay of the charge carriers. Such first order decay is typically observed for columnar materials and can be due to either trapping of charges or geminate recombination of electrons and holes [28].

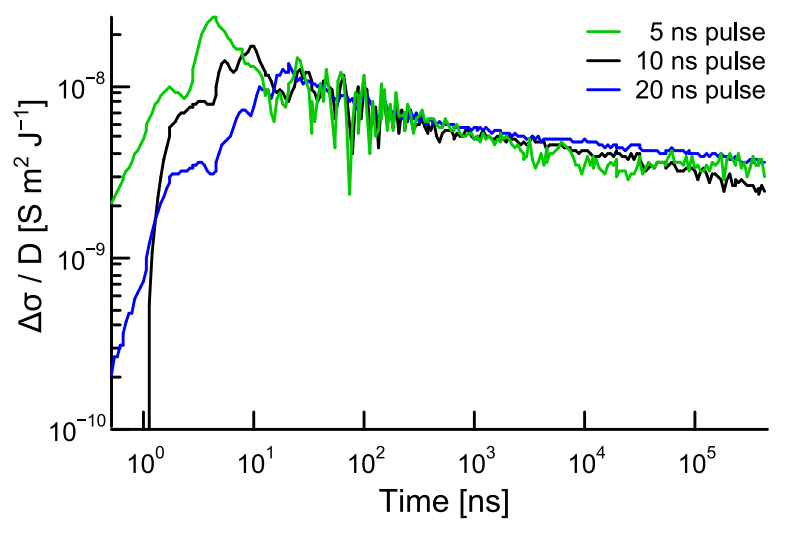

Figure 5: Variation of dose-normalized conductivity transients $(\Delta \sigma / D)$ with time for $\mathbf{T} 1$.
The lower limits of $\Sigma \mu_{\min }$ (the sum of the mobilities of the positive and negative charge carriers) were estimated from the relation $\Sigma \mu_{\min }=E_{p}(\Delta \sigma / D)$, where $E_{p}$ is the average electron-hole pair formation energy [28]. The mobility values obtained in this way at various temperatures are listed in Table 2 . The charge carrier mobility of $\mathbf{T} 1$ at $20^{\circ} \mathrm{C}$ was found to be $2.9 \times 10^{-3} \mathrm{~cm}^{2}$ $\mathrm{V}^{-1} \mathrm{~s}^{-1}$. When the sample was heated up to $110^{\circ} \mathrm{C}$, no significant difference was observed in the mobility value compared to that at $20{ }^{\circ} \mathrm{C}$, indicating good thermal stability of the supramolecular assembly of $\mathbf{T 1}$. A repeat measurement of mobility at $20{ }^{\circ} \mathrm{C}$ after the sample was annealed revealed a slightly higher value $\left(4.2 \times 10^{-3} \mathrm{~cm}^{2} \mathrm{~V}^{-1} \mathrm{~s}^{-1}\right)$, indicating an improvement of the supramolecular order in the material on annealing. It is interesting to note that the mobility value obtained for T1 is very close to that reported for non-regio regular alkyl-substituted polythiophenes $\left(\Sigma \mu_{\min }=7 \times 10^{-3} \mathrm{~cm}^{2} \mathrm{~V}^{-1} \mathrm{~s}^{-1}\right)$ [29], suggesting similar electronic coupling between oligothiophenes in the gelated $\pi$-stacks.

Table 2: Charge carrier mobilities of T1 at various temperatures in the sequence as measured in two experimental series.

\begin{tabular}{cccc}
$\mathrm{T}\left({ }^{\circ} \mathrm{C}\right)$ & $\begin{array}{c}\sum \mu_{\min } \\
\left(\mathrm{cm}^{2} \mathrm{~V}^{-1} \mathrm{~s}^{-1}\right)\end{array}$ & $\mathrm{T}\left({ }^{\circ} \mathrm{C}\right)$ & $\begin{array}{c}\sum \mu_{\min } \\
\left(\mathrm{cm}^{2} \mathrm{~V}^{-1} \mathrm{~s}^{-1}\right)\end{array}$ \\
\hline 20 & 0.0030 & 80 & 0.0024 \\
0 & 0.0032 & 100 & 0.0021 \\
-20 & 0.0031 & 110 & 0.0024 \\
-40 & 0.0030 & 100 & 0.0027 \\
-20 & 0.0030 & 80 & 0.0031 \\
0 & 0.0032 & 60 & 0.0034 \\
20 & 0.0029 & 40 & 0.0039 \\
40 & 0.0028 & 20 & 0.0042 \\
60 & 0.0026 & &
\end{tabular}




\section{Conclusion}

We have demonstrated the self-assembly and charge transport properties of a trialkoxybenzamide-functionalized quaterthiophene $\pi$-system. Our studies revealed the versatile and very effective gelation ability of the present system compared to the previously reported oligothiophene gelators. The critical gelation concentrations in numerous solvents are remarkably low and in few cases even in the range of supergelators. The impact of facile self-assembly of newly developed oligothiophene building block on its material properties is reflected in promising charge transport characteristics as revealed by PR-TRMC measurements. When compared with ordinary amorphous or crystalline organic semiconductors it should be taken into account that the oligothiophene moiety, which is responsible for charge transport, is only $19 \%$ of the total molecular weight of $\mathbf{T} 1$ and the remainder being made up by long alkyl chains that do not contribute to charge carrier mobility. AFM studies revealed self-sorted assembly of p-type oligothiophene gelator and n-type PCBM in their blend which might offer some prospect for photocurrent generation [30].

\section{Experimental}

Materials and methods. All reagents and solvents were purchased from commercial sources and purified by standard protocols [31]. Spectroscopic grade solvents were used as received for spectroscopic studies. ${ }^{1} \mathrm{H}$ NMR spectra were recorded on a $400 \mathrm{MHz}$ Bruker NMR spectrometer with tetramethylsilane (TMS) as the internal standard. UV-vis experiments were carried out on a Perkin-Elmer Lambda 40P spectrometer equipped with a Peltier system for temperature control.

Gelation tests. A measured amount of T1 and the appropriate solvent were taken together in a sample vial, heated to dissolve the sample and then left at room temperature. After 30 minutes, the gelation was tested by the "stable to inversion" method.

UV-vis spectroscopic studies. A stock solution of T1 was prepared in chloroform with $1 \mathrm{mM}$ concentration. A measured amount of stock solution was transferred to another vial and the solvent removed by blowing argon gas over it. To this vial, a measured amount of solvent such as $n$-heptane or cyclohexane was added to give the desired concentration and the mixture then gently heated in a warm water-bath to yield a homogeneous solution. The solutions were allowed to equilibrate at room temperature for $2 \mathrm{~h}$ before performing UV-vis experiments. For variable temperature studies, the temperature was changed from lower to higher values and the sample equilibrated for 10 min prior to each measurement after the particular temperature was reached.

\section{Atomic force microscopy (AFM) measurements. AFM} measurements were carried out under ambient conditions with a Veeco MultiMode ${ }^{\mathrm{TM}}$ Nanoscope IV system operating in the tapping mode in air. Silicon cantilevers (Olympus Corporation, Japan) with a resonance frequency of $\sim 300 \mathrm{kHz}$ and spring constant of $\sim 42 \mathrm{~N} / \mathrm{m}$ were used. A solution of T1 in methylcyclohexane $(\mathrm{MCH})$ with a concentration of $2 \times 10^{-3} \mathrm{M}$ was spincoated onto highly oriented pyrolytic graphite (HOPG) at $6000 \mathrm{rpm}$. The sample of a T1-PCBM mixture was prepared by spin-coating of $\mathrm{MCH}$ solution with a concentration of $5 \times$ $10^{-4} \mathrm{M}$ onto HOPG at $4000 \mathrm{rpm}$. The height of the observed fibers was determined by statistical analysis on the premise that the fibers lay on a thin film. Note that, due to the AFM tip broadening effect, the actual width of aggregates is usually smaller than the apparent one.

Pulse radiolysis time resolved microwave conductivity (PRTRMC) measurements. Conductivity measurements of quaterthiophene T1 were performed on a solid (powder) sample (about $32.5 \mathrm{mg}$ ) that was manually compressed into a perspex container. The sample was placed in a microwave cell, consisting of a piece of rectangular waveguide with inner dimensions of $3.55 \times 7.00 \mathrm{~mm}^{2}$ and short circuited with a metal end plate. The materials were uniformly ionized with a nanosecond pulse of $3 \mathrm{MeV}$ electrons from a Van de Graaff accelerator. The energy absorbed by the sample is accurately known from dosimetry and leads to the formation of a micromolar concentration of charge carriers (ca. $10^{-21} \mathrm{~m}^{-3}$ ). The change in conductivity due to creation of these charges was measured by time resolved microwave conductivity (TRMC) measurements [27].

Synthesis and characterization. 3,4,5-Tris(dodecyloxy)benzoyl chloride (5) and compounds 2, 3, 4 and 8 were prepared according to literature reported procedures and characterized by ${ }^{1} \mathrm{H}$ NMR and UV-vis spectroscopy. New compounds (6 and T1) were characterized by ${ }^{1} \mathrm{H}$ NMR, UV-vis, HRMS (ESI) and elemental analysis.

Tert-butyl 2-(thiophen-2-yl)ethylcarbamate (2). To a solution of 2-(thiophen-2-yl) ethylamine (1.63 g, $0.013 \mathrm{~mol})$ in $10 \mathrm{~mL} \mathrm{CHCl}_{3}$, a solution of Boc-anhydride (2.8 g, $\left.0.013 \mathrm{~mol}\right)$ in $10 \mathrm{~mL} \mathrm{CHCl}_{3}$ was added dropwise and the reaction mixture stirred under an inert atmosphere for $6 \mathrm{~h}$ at room temperature. The volatiles were then removed at reduced pressure to yield the crude 2 as a colourless oil (97\%). ${ }^{1} \mathrm{H}$ NMR (400 MHz, $\left.\mathrm{CDCl}_{3}, \mathrm{TMS}, 300 \mathrm{~K}\right): \delta(\mathrm{ppm})=7.15(\mathrm{~d}, 1 \mathrm{H}), 6.95-6.83(\mathrm{~m}$, $1 \mathrm{H}), 6.83(\mathrm{~m}, 1 \mathrm{H}), 4.65$ (broad peak, $1 \mathrm{H}), 3.38(\mathrm{t}, J=6.24 \mathrm{~Hz}$, $2 \mathrm{H}), 3.01(\mathrm{t}, J=6.68 \mathrm{~Hz}, 2 \mathrm{H}), 1.44(\mathrm{~s}, 9 \mathrm{H})$; UV-vis $\left(\mathrm{CH}_{2} \mathrm{Cl}_{2}\right)$ : $\lambda_{\max }(\varepsilon)=235 \mathrm{~nm}\left(0.697 \times 10^{4} \mathrm{M}^{-1} \mathrm{~cm}^{-1}\right)$. 
Tert-butyl 2-(5-bromothiophen-2-yl)ethylcarbamate (3). To an ice-cold solution of compound $2(0.77 \mathrm{~g}, 3.38 \mathrm{mmol})$ in $10 \mathrm{~mL}$ DMF, a solution of NBS $(0.603 \mathrm{~g}, 3.38 \mathrm{mmol})$ in $5 \mathrm{~mL}$ DMF was added dropwise. After the addition was complete, the reaction mixture was stirred at room temperature for a further $12 \mathrm{~h}$, then poured into $100 \mathrm{~mL}$ water and extracted with $(2 \times 30)$ $\mathrm{mL}$ diethylether. The combined organic layer was dried over anhydrous $\mathrm{Na}_{2} \mathrm{SO}_{4}$ and solvent removed to give the crude product as a light brown oil $(90 \%)$ which was used in the next step without further purification. ${ }^{1} \mathrm{H} \mathrm{NMR}\left(400 \mathrm{MHz}, \mathrm{CDCl}_{3}\right.$, TMS, $300 \mathrm{~K}): \delta(\mathrm{ppm})=6.88(\mathrm{~d}, J=3.64 \mathrm{~Hz}, 1 \mathrm{H}), 6.59(\mathrm{~d}, J=3.72$ $\mathrm{Hz}, 1 \mathrm{H}), 4.63$ (broad peak, 1H), 3.35 (t, $J=5.44 \mathrm{~Hz}, 2 \mathrm{H}), 2.93$ $(\mathrm{t}, J=6.60 \mathrm{~Hz}, 2 \mathrm{H}), 1.44(\mathrm{~s}, 9 \mathrm{H}) ; \mathrm{UV}$-vis $\left(\mathrm{CH}_{2} \mathrm{Cl}_{2}\right): \lambda_{\max }(\varepsilon)=$ $238 \mathrm{~nm}\left(0.735 \times 10^{4} \mathrm{M}^{-1} \mathrm{~cm}^{-1}\right)$.

2-(5-Bromothiophen-2-yl)ethylamine (4). To a solution of tert-butyl 2-(5-bromothiophene-2-yl)ethylcarbamate (3) in $5 \mathrm{~mL} \mathrm{CH}_{2} \mathrm{Cl}_{2}, 5 \mathrm{~mL}$ TFA was added and the reaction mixture stirred at $\mathrm{rt}$ under an argon atmosphere for $2 \mathrm{~h}$. The volatiles were then removed under reduced pressure to afford the crude product as a light brown oil (96\%) which was used in the next step without further purification. ${ }^{1} \mathrm{H} \mathrm{NMR}\left(400 \mathrm{MHz}, \mathrm{CDCl}_{3}\right.$, TMS, $300 \mathrm{~K}): \delta(\mathrm{ppm})=7.48($ broad s, $2 \mathrm{H}) ; 6.90(\mathrm{~d}, J=3.72$ $\mathrm{Hz}, 1 \mathrm{H}), 6.67$ (d, $J=3.64 \mathrm{~Hz}, 1 \mathrm{H}), 3.28(\mathrm{~m}, 2 \mathrm{H}), 3.15$ (t, $J=$ $7.04 \mathrm{~Hz}, 2 \mathrm{H})$; UV-vis $\left(\mathrm{CH}_{2} \mathrm{Cl}_{2}\right): \lambda_{\max }(\varepsilon)=238 \mathrm{~nm}(0.741 \times$ $\left.10^{4} \mathrm{M}^{-1} \mathrm{~cm}^{-1}\right)$.

N-2-(5-Bromothiophen-2-yl)ethyl) 3,4,5-tris(dodecyloxy)benzamide (6). Compound $4(2.94 \mathrm{mmol})$ was dissolved in $5 \mathrm{~mL}$ dry $\mathrm{CH}_{2} \mathrm{Cl}_{2}$ and cooled in an ice-bath. To this cold solution, $4 \mathrm{~mL}$ triethylamine was added slowly. The resulting mixture was ice-cooled for an additional 10 minutes and then a solution of compound 5 in $10 \mathrm{~mL}$ dry $\mathrm{CH}_{2} \mathrm{Cl}_{2}$ was added dropwise. The reaction mixture was stirred at $\mathrm{rt}$ for $12 \mathrm{~h}$, diluted with a further $25 \mathrm{~mL} \mathrm{CH}_{2} \mathrm{Cl}_{2}$ and washed successively with water $(2 \times 50 \mathrm{~mL})$, dil. $\mathrm{HCl}(2 \times 50 \mathrm{~mL})$ and finally with $50 \mathrm{~mL}$ brine. The combined organic layer was dried over anhydrous $\mathrm{Na}_{2} \mathrm{SO}_{4}$ and solvent removed under reduced pressure to give the crude product as a light yellow solid which was purified by column chromatography on silica gel with $\mathrm{CH}_{2} \mathrm{Cl}_{2}$ as eluent. The product was further purified by dissolving it in $5 \mathrm{~mL}$ $\mathrm{CH}_{2} \mathrm{Cl}_{2}$ and re-precipitating from $200 \mathrm{~mL} n$-hexane to yield a white solid (67\%). M.p. $76-78{ }^{\circ} \mathrm{C} ;{ }^{1} \mathrm{H}$ NMR $\left(400 \mathrm{MHz}, \mathrm{CDCl}_{3}\right.$, TMS, $300 \mathrm{~K}): \delta(\mathrm{ppm})=6.91-6.90(\mathrm{~m}, 3 \mathrm{H}), 6.64(\mathrm{~d}, J=3.64$ $\mathrm{Hz}, 1 \mathrm{H}), 6.13$ (broad s, 1H), 4.00-3.96 (m, 6H), 3.69-3.63 (m, $2 \mathrm{H}), 3.07(\mathrm{t}, J=6.44 \mathrm{~Hz}, 2 \mathrm{H}), 1.76-1.48(\mathrm{~m}, 60 \mathrm{H}), 0.88$ (t, $J=$ $7.00 \mathrm{~Hz}, 9 \mathrm{H})$; UV-vis $\left(\mathrm{CH}_{2} \mathrm{Cl}_{2}\right): \lambda_{\max }(\varepsilon)=257 \mathrm{~nm}(1.381 \times$ $\left.10^{4} \mathrm{M}^{-1} \mathrm{~cm}^{-1}\right), 290 \mathrm{~nm}\left(0.296 \times 10^{4} \mathrm{M}^{-1} \mathrm{~cm}^{-1}\right)$; HRMS (ESI): $\mathrm{m} / \mathrm{z}$ calcd for $\mathrm{C}_{49} \mathrm{H}_{85} \mathrm{BrNO}_{4} \mathrm{~S}[M+2 \mathrm{H}]^{+}: 862.5372$; found: 862.5377; elemental analysis: calcd for $\mathrm{C}_{49} \mathrm{H}_{85} \mathrm{BrNO}_{4} \mathrm{~S}$ : C, 68.18, H, 9.81, N, 1.62, found: C, 67.93, H, 9.70, N, 1.76.
Quaterthiophene gelator T1. $n$-BuLi $(360 \mu \mathrm{L}$ in $2 \mathrm{~mL}$ dry THF) was added to a round-bottomed flask, flushed with argon gas for 15 minutes, and then cooled to $0^{\circ} \mathrm{C}$ in an ice-bath. To this solution, a solution of $2,2^{\prime}$-bithiophene in dry THF (68.0 $\mathrm{mg}$ in $5 \mathrm{~mL}$ ) was added dropwise under continuous flow of argon. A white solid precipitate was formed. The reaction mixture was stirred at room temperature for $1 \mathrm{~h}$ and then immersed in an ice-bath. To this cold solution, $400 \mu \mathrm{L} \mathrm{Bu}_{3} \mathrm{SnCl}$ was added which caused the precipitate to dissolve immediately. The reaction mixture was stirred at room for further $12 \mathrm{~h}$ under an argon atmosphere. The volatiles were removed under reduced pressure to give the crude product as a white pasty mass. The crude product was dissolved in $20 \mathrm{~mL}$ dry DMF, compound 9 added and the flask evacuated, purged three times with argon and $\sim 15 \mathrm{mg}$ of the Pd-catalyst added under continuous flow of argon. The reaction mixture was then heated at $80^{\circ} \mathrm{C}$ for $8 \mathrm{~h}$ under an argon atmosphere. It was observed that an orange precipitate appeared within first $30 \mathrm{~min}$, which almost dissolved as the reaction progressed. After $8 \mathrm{~h}$ the reaction was stopped, cooled to $\mathrm{rt}$ and poured into $200 \mathrm{~mL} \mathrm{MeOH}$. A yellowish orange precipitate was separated by filtration and dried in vacuum to give the crude product as a yellow solid. The crude product was purified by column chromatography on silica gel with $2 \%$ methanol in chloroform as eluent to afford the pure product as a yellow solid (78\%). M.p. $144{ }^{\circ} \mathrm{C} .{ }^{1} \mathrm{H}$ NMR (400 $\mathrm{MHz}, \mathrm{CDCl}_{3}$, TMS, $\left.300 \mathrm{~K}\right): \delta(\mathrm{ppm})=7.04-7.00(\mathrm{~m}, 6 \mathrm{H}), 6.79$ (s, 4H), $6.18(\mathrm{~s}, 2 \mathrm{H}), 6.78-6.75(\mathrm{~m}, 2 \mathrm{H}), 3.99-3.95(\mathrm{~m}, 12 \mathrm{H})$, 3.73-3.69 (m, 4H), 3.14-3.10 (m, 4H), 1.81-1.25 (m, 120H), 0.89-0.85 (m, 18H); UV-vis $\left(\mathrm{CH}_{2} \mathrm{Cl}_{2}\right): \lambda_{\max }(\varepsilon)=262 \mathrm{~nm}(1.76$ $\left.\times 10^{4} \mathrm{M}^{-1} \mathrm{~cm}^{-1}\right), 405 \mathrm{~nm}\left(2.90 \times 10^{4} \mathrm{M}^{-1} \mathrm{~cm}^{-1}\right)$; HRMS (ESI): $\mathrm{m} / \mathrm{z}$ calcd for $\mathrm{C}_{106} \mathrm{H}_{172} \mathrm{~N}_{2} \mathrm{Na}_{1} \mathrm{O}_{8} \mathrm{~S}_{4}[M+\mathrm{Na}]^{+}$ :1752.1881; found: 1752.1920; MS (MALDI) m/z calcd for $\mathrm{C}_{106} \mathrm{H}_{172} \mathrm{~N}_{2} \mathrm{O}_{8} \mathrm{~S}_{4}[\mathrm{M}+\mathrm{H}]^{+}$1730.206, found: 1730.265 ; elemental analysis: calcd for $\mathrm{C}_{106} \mathrm{H}_{172} \mathrm{~N}_{2} \mathrm{Na}_{1} \mathrm{O}_{8} \mathrm{~S}_{4}$ : C, 73.56, $\mathrm{H}$, 10.02, N, 1.62, found: C, 73.32, H, 9.81, N, 1.73.

\section{Acknowledgement}

SG thanks the Alexander von Humboldt foundation for a postdoctoral fellowship.

\section{References}

1. Lehn, J.-M. Supramolecular Chemistry - Concepts and Perspectives; Wiley-VCH: Weinheim, 1995.

2. Hoeben, F. M.; Jonkheijm, P.; Meijer, E. W.; Schenning, A. P. H. J. Chem. Rev. 2005, 105, 1491-1546. doi:10.1021/cr030070z

3. Fages, F. Low Molecular Mass Gelators; Topics in Current Chemistry, Vol. 256; Springer: Berlin, Germany, 2005. doi:10.1007/b105250

4. Bouas-Laurent, H.; Desvergne, J.-P. In Molecular Gels: Materials with Self-Assembled Fibrilla Networks; Weiss, G. R.; Terech, P., Eds.; Chapter 12; Springer: Netherlands, 2006.

5. Ajayaghosh, A.; Praveen, V. K. Acc. Chem. Res. 2007, 40, 644-665. doi:10.1021/ar7000364 
6. Prasanthkumar, S.; Saeki, A.; Seki, S.; Ajayaghosh, A. J. Am. Chem. Soc. 2010, 132, 8866-8867. doi:10.1021/ja103685j

7. Ajayaghosh, A.; Varghese, R.; Mahesh, S.; Praveen, V. K. Angew. Chem., Int. Ed. 2006, 45, 7729-7732. doi:10.1002/anie.200603238

8. Engelkamp, H.; Middelbeek, S.; Nolte, R. J. M. Science 1999, 284, 785-790. doi:10.1126/science.284.5415.785

9. Malik, S.; Kawano, S-i.; Fujita, N.; Shinkai, S. Tetrahedron 2007, 63, 7326-7333. doi:10.1016/j.tet.2007.05.027

10. Sugiyasu, K.; Fujita, N.; Shinkai, S. Angew. Chem., Int. Ed. 2004, 43, 1229-1233. doi:10.1002/anie.200352458

11. Mukhopadhyay, P.; Iwashita, Y.; Shirakawa, M.; Kawano, S-i.; Fujita, N.; Shinkai, S. Angew. Chem., Int. Ed. 2006, 45, 1592-1595. doi:10.1002/anie.200503158

12. Li, X.-Q.; Stepanenko, V.; Chen, Z.; Prins, P.; Siebbeles, L. D. A.; Würthner, F. Chem. Commun. 2006, 3871-3873. doi:10.1039/b611422a

13. Del Guerzo, A.; Olive, A. G. L.; Reichwagen, J.; Hopf, H.; Desvergne, J.-P. J. Am. Chem. Soc. 2005, 127, 17984-17985. doi:10.1021/ja0566228

14. Desvergne, J. P.; Olive, A. G. L.; Sangeetha, N. M.; Reichwagen, J.; Hopf, H.; Del Guerzo, A. Pure Appl. Chem. 2006, 78, 2333-2339. doi:10.1351/pac200678122333

15. Yagai, S.; Ishii, M.; Karatsu, T.; Kitamura, A. Angew. Chem., Int. Ed. 2007, 46, 8005-8009. doi:10.1002/anie.200702263

16. Yao, S.; Beginn, U.; Greß, T.; Lysetska, M.; Würthner, F. J. Am. Chem. Soc. 2004, 126, 8336-8348. doi:10.1021/ja0496367

17. Mishra, A.; Ma, C.-Q.; Bäuerle, P. Chem. Rev. 2009, 109, 1141-1276. doi:10.1021/cr8004229

18. Schoonbeek, F. S.; Van Esch, J. H.; Wegewijs, B.; Rep, D. B. A.; De Haas, M. P.; Klapwijk, T. M.; Kellogg, R. M.; Feringa, B. L. Angew. Chem., Int. Ed. 1999, 38, 1393-1397. doi:10.1002/(SICI)1521-3773(19990517)38:10<1393::AID-ANIE1393>3 .0.CO;2-H

19. Kawano, S.; Fujita, N.; Shinkai, S. Chem.-Eur. J. 2005, 11, 4735-4742. doi:10.1002/chem.200500274

20. Ghosh, S.; Li, X.-Q.; Stepanenko, V.; Würthner, F. Chem.-Eur. J. 2008, 14, 11343-11357. doi:10.1002/chem.200801454

21. Würthner, F.; Bauer, C.; Stepanenko, V.; Yagai, S. Adv. Mater. 2008, 20, 1695-1698. doi:10.1002/adma.200702935

22. Venkatachalam, T. K.; Sudbeck, E. A.; Uckun, F. M. Tetrahedron Lett. 2001, 42, 6629-6632. doi:10.1016/s0040-4039(01)01290-4

23. Langeveld-Voss, B. M. W.; Waterval, R. J. M.; Janssen, R. A. J.; Meijer, E. W. Macromolecules 1999, 32, 227-230. doi:10.1021/ma981349y

24. Nelson, J. Curr. Opin. Solid State Mater. Sci. 2002, 6, 87-95. doi:10.1016/s1359-0286(02)00006-2

25. Van Duren, J. K. J.; Yang, X.; Loos, J.; Bulle-Lieuwma, C. W. T.; Sieval, A. B.; Hummelen, J. C.; Janssen, R. A. J. Adv. Funct. Mater. 2004, 14, 425-434. doi:10.1002/adfm.200305049

26. Wicklein, A.; Ghosh, S.; Sommer, M.; Würthner, F.; Thelakkat, M. ACS Nano 2009, 3, 1107-1114. doi:10.1021/nn9001165

27. Warman, J. M.; de Haas, M. P.; Dicker, G.; Grozema, F. C.; Piris, J.; Debije, M. G. Chem. Mater. 2004, 16, 4600-4609. doi:10.1021/cm049577w

28. Warman, J. M.; Van de Craats, A. M. Mol. Cryst. Liq. Cryst. 2003, 396, 41-72. doi:10.1080/15421400390213186

29. Van der Laan, G. P.; Haas, M. P. D.; Buik, A.; De Ruiter, B. Synth. Met. 1993, 55, 4930-4935. doi:10.1016/0379-6779(93)90841-J
30. Yamamoto, Y.; Fukushima, T.; Suna, Y.; Ishii, N.; Saeki, A.; Seki, S.; Tagawa, S.; Taniguchi, M.; Kawai, T.; Aida, T. Science 2006, 314, 1761-1764. doi:10.1126/science.1134441

31. Perrin, D. D.; Armarego, W. L. F.; Perrin, D. R. Purification of Laboratory chemicals, 2nd ed.; Pergamon: Oxford, 1980.

\section{License and Terms}

This is an Open Access article under the terms of the Creative Commons Attribution License

(http://creativecommons.org/licenses/by/2.0), which permits unrestricted use, distribution, and reproduction in any medium, provided the original work is properly cited.

The license is subject to the Beilstein Journal of Organic Chemistry terms and conditions:

(http://www.beilstein-journals.org/bjoc)

The definitive version of this article is the electronic one which can be found at: doi:10.3762/bjoc. 6.122 